\title{
QK 329
}

.M613

\section{Morton, Friedrich}

Beiträge zur Kenntnis der flora von Suddalmatien 


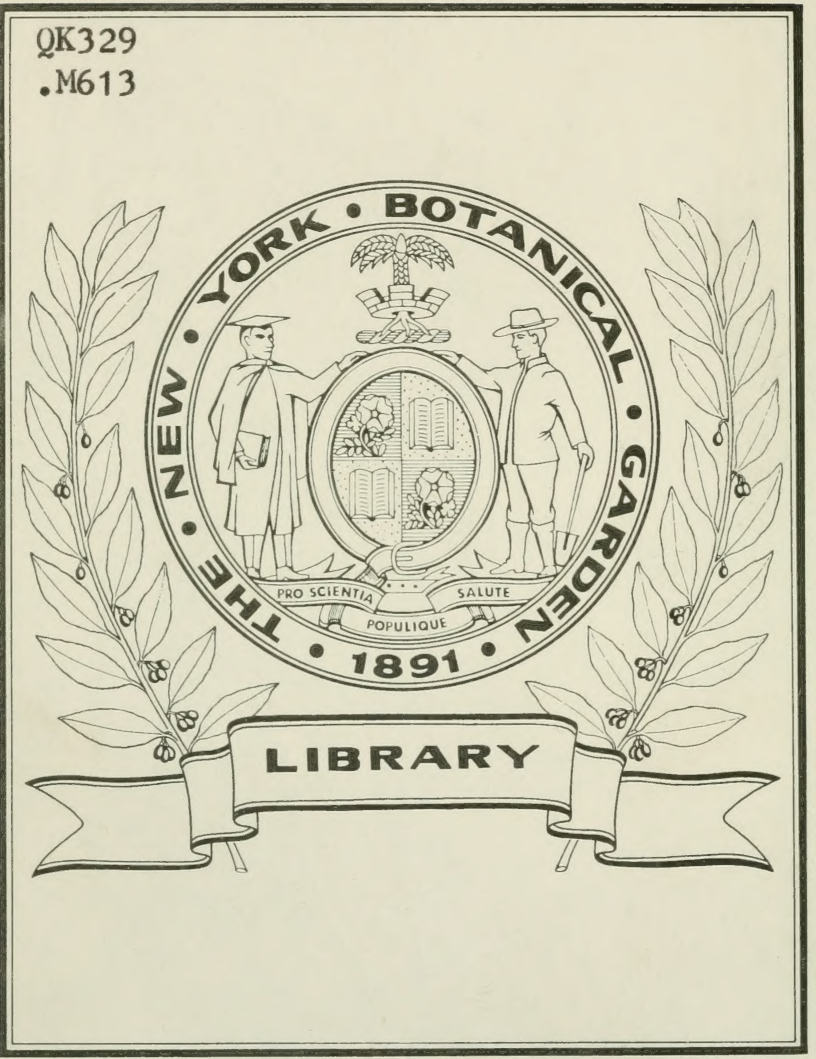



Beiträge zur Kenntnis der Flora von Süddalmatien.

Von Dr. Friedrich Morton (Wien).

(Mit 3 Abbildungen.) 



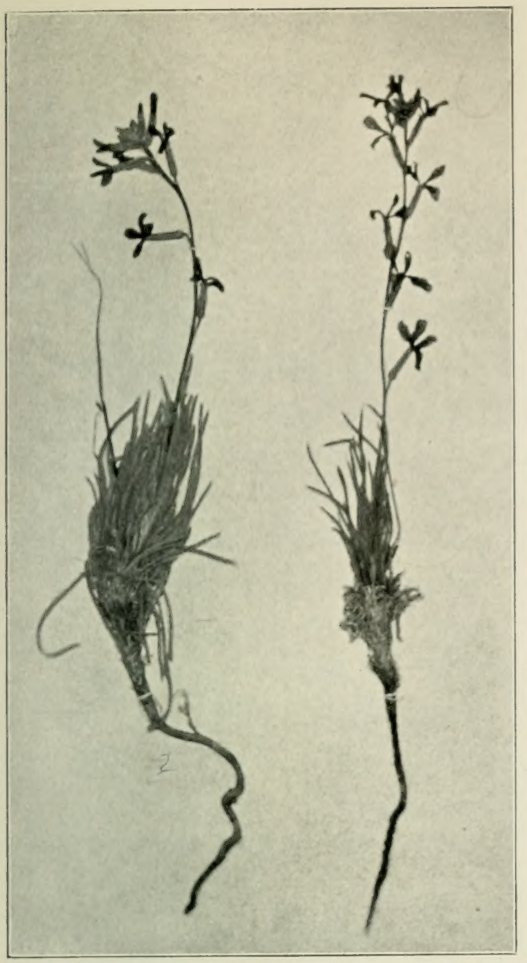

Abb. 1.

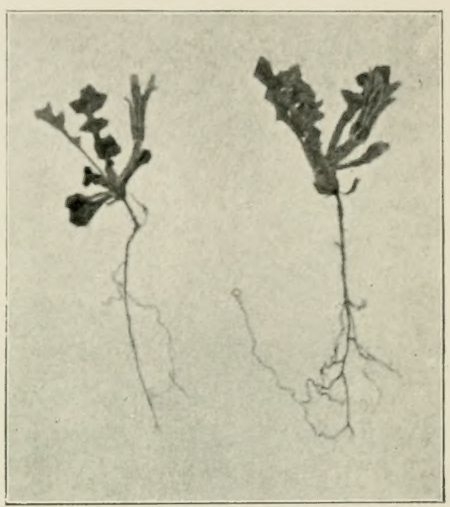

Abb. 3.

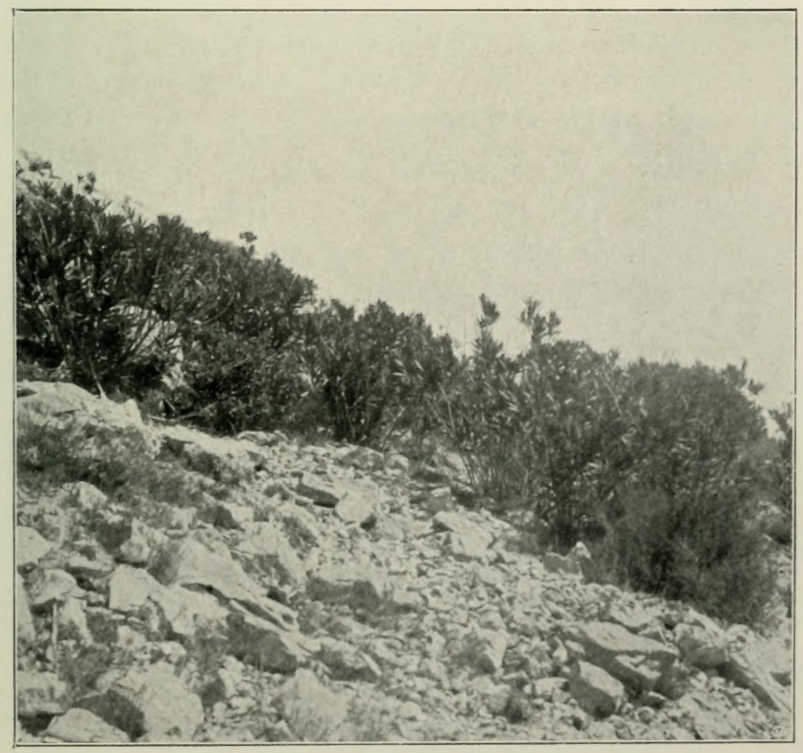

Abb. 2. 

Im nachfolgenden gebe ich eine Reihe von Pflanzenfunden bekannt, die von mir gelegentlich pflanzengeographischer Arbeiten im südlichen Dalmatien gemacht wurden.

Polypodium vulgare L. var. serratum Willd. Insel Curzola: auf Kalkfelsen in der Formation der Garrigue zwischen Curzola und Lombarda. Asplenium acutum Bory. Am Südabfall des Koziak bei Spalato in der Macchie oberhalb Sućurac.

Quercus coccifera L. Halbinsel Sabbioncello : am Südabfall des Monte Vipera vom Meere bis gegen $300 \mathrm{~m}$ als Macchienelement. Stellenweise noch in mächtigen, baumförmigen Exemplaren.

Ranunculus calthaefolius (Rchb.) Bl. N. Sch. Halbinsel Sabbioncello: in der Formation der steinigen Trift auf dem Monte Vipera.

Cardamine maritima Portenschl. Halbinsel Sabbioncello: an Steinmauern oberhalb Orebić.

Hesperis glutinosa Vis. Im Kalkgeröll am Fuße der Steilwände des Koziak bei Spalato; in der Formation der steinigen Triften auf dem Monte Vipera.

Matthiola tristis L., R. Br. var. italica Conti, subv. typica Conti. Halbinsel Sabbioncello: in der Formation der steinigen Triften am Südabfall des Monte Vipera. - Matthiola tristis erscheint als eine sehr formenreiche Pflanze, die nach Conti (Classification et distribution des espèces européennes du genre Matthiola in „Bulletin de L'Herbier Boissier“, 'l'ome V, 1897, p. 31-59) in fünf Unterarten zerfällt, die den Verbreitungsbezirken der Art entsprechen. (Alpiner, iberisch-provençaler, italisch-dalmatinischer, sizilischer und Balkanbezirk.) Die Pflanze des italisch-dalmatinischen Bezirkes gehört zur var. italica Conti, die durch graugrüne Färbung, einfachen, nicht verzweigten, blattlosen Stamm und durch lineale, in Rosetten angeordnete Blätter gegenüber den übrigen Unterarten gut gekennzeichnet erscheint. (Abb. 1.) Von Conti wird sie innerhalb unserer Monarchie für Trebinje angegeben.

Vesicaria graeca Reut. Häufig am Fuße per Steilwände des Koziak bei Spalato und auf Schutthalden am SO-Abfall des Monte Vipera.

Anthyllis Spruneri Boiss. Insel Curzola: in der Formation der Garrigue zwischen Curzola und Lombarda. 
Nerium oleander L. Halbinsel Sabbioncello: oberhalb des Dorfes Lampalovo am Südhange des Monte Vipera bildet Nerium ca. zwischen 200 und $300 \mathrm{~m}$ eine üppige Garrigue und ist mit Quercus coccifera, Euphorbia spinosa, Laurus nobilis, Coronilla emeroides u. a. vergesellschaftet. (Abb. 2.)

Hyoseris scabra L. ${ }^{1}$ ) Insel Curzola: in der Formation der Garrigue und auf Ruderalplätzen zwischen Curzola und Lombarda. Auf einem Kalkfelsen fanden sich Zwergexemplare mit nur einer Blüte und nur $14 \mathrm{~mm}$ Höhe! (Abb. 3.)

Fritillaria tenella M. B. Insel Curzola: in der Formation der Garrigue zwischen Curzola und Lombarda.

Hyacinthus dalmaticus Backer. Halbinsel Sabbioncello: in großen Mengen am Südhang des Monte Vipera in einer kurzgrasigen Mulde bei ca. $750 \mathrm{~m}$.

Narcissus angustifolius Curt. Halbinsel Sabbioncello: in der Formation der steinigen Triften am Südhange des Monte Vipera.

Carex distachya Desf. Am Südhange des Koziak bei Spalato, am Fuße der Steilwände.

Avena convoluta Presl. Am Süảhange des Koziak bei der Kirche Sv. Gospoja.

Sesleria tenuifolia Schrad. ${ }^{2}$ ) Halbinsel Sabbioncello: in der Formation der steinigen Triften am Südhang des Monte Vipera.

Orchis provincialis ${ }^{3}$ ) Balb. In den Macchien oberhalb Sućurac am Südhange des Koziak; auf Schutthalden am SO-Abhange des Monte Vipera bis $650 \mathrm{~m}$.

Orchis quadripunctata $\mathrm{Cyr}^{3}{ }^{3}$ ) In Ölgärten oberhalb Orebić.

Orchis Spitzelii Saut. ${ }^{3}$ ) In der Formation des mediterranen Schwarzföhrenwaldes am S0-Hange des Monte Vipera bis $800 \mathrm{~m}$.
1) revid. A. G in $\mathrm{z} b$ e $\mathrm{r} g$ er.
2) revid. E. $\mathrm{H} \mathrm{a} \mathrm{ckel}$.
3) revid. H. Flei s c h m a n n. 

Morton, Friedrich/Beitrage zur Kenntnis
|

35185001101839 
